\title{
Stabilization of the $\zeta-\mathrm{Cu}_{10} \mathrm{Sn}_{3}$ Phase by $\mathrm{Ni}$ at Soldering-Relevant Temperatures
}

\author{
C. WIESER,${ }^{1,2}$ W. HÜGEL ${ }^{2}$ S. MARTIN,${ }^{1}$ J. FREUDENBERGER,${ }^{1,3}$ \\ and A. LEINEWEBER (1) ${ }^{1,4}$
}

1.-Institute of Materials Science, TU Bergakademie, Gustav-Zeuner-Str. 5, 09599 Freiberg, Germany. 2.-Automotive Electronics/Engineering Assembly Interconnect Technology (AE/EAI), Robert Bosch GmbH, Robert-Bosch-Str. 2, 71701 Schwieberdingen, Germany. 3.-Leibniz IFW Dresden, Institute for Metallic Materials, Helmholtzstr. 20, 01069 Dresden, Germany. 4.—e-mail: andreas.leineweber@iww.tu-freiberg.de

A current issue in electrical engineering is the enhancement of the quality of solder joints. This is mainly associated with the ongoing electrification of transportation as well as the miniaturization of (power) electronics. For the reliability of solder joints, intermetallic phases in the microstructure of the solder are of great importance. The formation of the intermetallic phases in the $\mathrm{Cu}$-Sn solder system was investigated for different annealing temperatures between $472 \mathrm{~K}$ and $623 \mathrm{~K}$ using pure $\mathrm{Cu}$ as well as $\mathrm{Cu}-1 \mathrm{at} . \% \mathrm{Ni}$ and $\mathrm{Cu}$ 3 at.\% Ni substrate materials. These are relevant for lead frame materials in electronic components. The $\mathrm{Cu}$ and $\mathrm{Cu}-\mathrm{Ni}$ alloys were in contact to galvanic plated Sn. This work is focused on the unexpected formation of the hexagonal $\zeta-(\mathrm{Cu}, \mathrm{Ni})_{10} \mathrm{Sn}_{3}$ phase at annealing temperatures of $523-623 \mathrm{~K}$, which is far below the eutectoid decomposition temperature of binary $\zeta-\mathrm{Cu}_{10} \mathrm{Sn}_{3}$ of about $855 \mathrm{~K}$. By using scanning electron microscopy, energy dispersive X-ray spectroscopy, electron backscatter diffraction and X-ray diffraction the presence of the $\zeta$ phase was confirmed and its structural properties were analyzed.

Key words: Intermetallic phases, soldering, $\mathrm{Cu}-\mathrm{Ni}-\mathrm{Sn}$ compounds, $\mathrm{x}$-ray diffraction

\section{INTRODUCTION}

The ongoing electrification leads to an increase in the number of electronic devices, which possess sophisticated functionality as well as enhanced performance. In consequence, the requirements with respect to strength and reliability increase. Therefore, the lead frame (substrate) material of electronic components has to withstand higher (mechanical) loads and, therefore, often additional alloying elements such as $\mathrm{Ni}$ are added to the pure $\mathrm{Cu}$ substrate material for mechanical strengthening.

If pure $\mathrm{Cu}$ substrate materials are in contact with Sn solders at typical reflow soldering temperatures

(Received December 6, 2019; accepted February 21, 2020; published online March 16, 2020) (e.g. $523 \mathrm{~K}$ ), formation of $\eta$ - $\mathrm{Cu}_{6} \mathrm{Sn}_{5}$ and $\varepsilon-\mathrm{Cu}_{3} \mathrm{Sn}$ (see Table I) intermetallics takes place. The addition of minor amounts of $\mathrm{Ni}$ to $\mathrm{Cu}$ is widely reported to have a strong influence on the phase composition and, in particular, on the phase formation kinetics, affecting the microstructure considerably. ${ }^{1-9}$ The phase formation scheme remains the same, but it has been reported that $\mathrm{Ni}$ promotes growth of the $\eta$ phase at the cost of the $\varepsilon$ phase. Moreover, $\mathrm{Ni}$ is often added to solder pastes and its influence on intermetallic formation was also investigated in different research works. ${ }^{10-15}$ It has been observed that the microstructural changes induced by $\mathrm{Ni}$ in either the substrate or the solder paste can significantly affect the reliability of solder joints. ${ }^{16}$

The present work is particularly focused on the occurrence of the $\zeta-(\mathrm{Cu}, \mathrm{Ni})_{10} \mathrm{Sn}_{3}$ phase (deriving from the $\zeta-\mathrm{Cu}_{10} \mathrm{Sn}_{3}$ phase) upon interaction of $\mathrm{Sn}$ with $\mathrm{Cu}-\mathrm{Ni}$ alloys at temperatures down to $523 \mathrm{~K}$. 
Table I. Crystallographic data for the intermetallic phases in the Cu-Sn system relevant for the present work

\begin{tabular}{|c|c|c|c|c|}
\hline Phase & Stoichiometry & Space group & Lattice parameters & References \\
\hline $\mathrm{Cu}$ & $\mathrm{Cu}$ & $F m \overline{3} m$ & $a=3.61 \AA$ & 27 \\
\hline$\zeta$ & $\mathrm{Cu}_{10} \mathrm{Sn}_{3}$ & $\mathrm{PG}_{3}$ & $\begin{array}{l}a=7.330 \AA \\
c=7.864 \AA\end{array}$ & 25 \\
\hline$\zeta$ & $\mathrm{Cu}_{10} \mathrm{Sn}_{3}$ & $P 6_{3} / m$ & $\begin{array}{c}a=7.313 \AA \\
c=7.87 \AA\end{array}$ & 26 \\
\hline$\zeta$ & $\mathrm{Cu}_{10} \mathrm{Sn}_{3}$ & $P \overline{3} 1 m$ & $\begin{array}{c}a=7.331 \AA \\
c=7.87 \AA\end{array}$ & 24 \\
\hline$\gamma$ & $\mathrm{Cu}_{3} \mathrm{Sn}$ & $F m \overline{3} m$ & $a=6.1176 \AA$ & 28 \\
\hline$\varepsilon$ & $\mathrm{Cu}_{3} \mathrm{Sn}$ & Pnmm & $\begin{array}{l}a=4.772 \AA \\
b=5.514 \AA \\
c=4.335 \AA\end{array}$ & 29 \\
\hline$\varepsilon$ & $\mathrm{Cu}_{3} \mathrm{Sn}^{\mathrm{a}}$ & $\mathrm{Cmcm}$ & $\begin{array}{c}a=5.529 \AA \approx b_{\text {Pnmm }} \\
b=47.75 \AA \approx 10 a_{\text {Pnmm }} \\
c=4.323 \AA\end{array}$ & 30 \\
\hline$\varepsilon$ & $\mathrm{Cu}_{3} \mathrm{Sn}^{\mathrm{a}}$ & $\mathrm{Cmcm}$ & 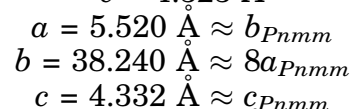 & 31 \\
\hline$\eta$ & $\mathrm{Cu}_{6} \mathrm{Sn}_{5}^{\mathrm{b}}$ & $P 6_{3} / m m c$ & $\begin{array}{l}a=4.190 \AA \\
c=5.086 \AA\end{array}$ & 32 \\
\hline$(\beta-) \mathrm{Sn}$ & $\mathrm{Sn}$ & $I 4_{1} /$ amd & $\begin{array}{l}a=5.831 \AA \\
c=3.182 \AA\end{array}$ & 33 \\
\hline
\end{tabular}

${ }_{\varepsilon-1} \mathrm{Cu}_{3} \mathrm{Sn}$ contains periodic antiphase boundaries, which are not considered by the Knödler model. ${ }^{29}$ Watanabe et al. ${ }^{30}$ and Mueller and Lidin $^{31}$ consider this issue by creating superstructures containing such antiphase boundaries

${ }^{b}$ In contrast to early descriptions of the atomic structure as simple NiAs type ${ }^{32}$ this disordered high-temperature $\eta$ phase can be described as $\mathrm{Cu}(1) \mathrm{Cu}(2)_{\sim 0.2} \mathrm{Sn}$ instead of $\mathrm{Cu}_{6} \mathrm{Sn}_{5}$. The $\mathrm{Sn}$ atoms form a hexagonally closed packed arrangement with $\mathrm{Cu}(1)$ occupying the octahedral sites, whereas the $\mathrm{Cu}(2)$ atoms occupy one-fifth of the trigonal bipyramidal sites formed by $\mathrm{Sn}^{34}$

These temperatures are much lower than the lowtemperature stability limit of the binary $\zeta-\mathrm{Cu}_{10} \mathrm{Sn}_{3}$ phase of $855 \mathrm{~K}^{17}$ (Fig. 1) or $862 \mathrm{~K}^{18 *}$ This can be regarded as a stabilization of the $\zeta$ phase by $\mathrm{Ni}$ and agrees with an earlier work of Wachtel and Bayer, ${ }^{20}$ depicting a vertical section in the $\mathrm{Cu}-\mathrm{Ni}$-Sn system at 25 at.\% Sn, indicating stability of the $\zeta$ phase down to $500 \mathrm{~K}$. However, Wachtel and Bayer ${ }^{20}$ presented no experimental details supporting their vertical section and in particular demonstrating the stabilization of the $\zeta$ phase by the presence of Ni.

The stabilization of the $\zeta$ phase towards low temperatures by presence of $\mathrm{Ni}$ was, however, widely ignored in later works. Such a stabilization was e.g. regarded to be unlikely by $\mathrm{Gosh}^{22}$ in a review on the constitution of the $\mathrm{Cu}-\mathrm{Ni}-\mathrm{Sn}$ system. In contrast to this, an experimental assessment of the $\mathrm{Cu}-\mathrm{Ni}$-Sn system by Schmetterer et al. ${ }^{23}$ confirmed such a stabilization. Experimental data (SEM/EDS and XRD) from this work demonstrated that the ternary $\zeta-(\mathrm{Cu}, \mathrm{Ni})_{10} \mathrm{Sn}_{3}$ phase can form at $773 \mathrm{~K}$ and even $673 \mathrm{~K}$, which is in agreement with Wachtel and Bayer $^{20}$ (see above). These findings

*Note that a metastable $\zeta$ phase may also form at $573 \mathrm{~K}$ by a discontinuous precipitation process upon decomposition of the supersaturated fcc-Cu-Sn solid solution. ${ }^{19}$ were considered for the construction of corresponding isothermal sections of the $\mathrm{Cu}-\mathrm{Ni}$-Sn system. ${ }^{23}$ Another isothermal section at $493 \mathrm{~K}$ also showed the ternary $\zeta$ phase, ${ }^{23}$ which was, however, not backed by new experiments but only adopted from the above mentioned vertical section of Wachtel and Bayer. $^{20}$

In the literature, three works exist elucidating the crystal structure of a binary $\zeta$ phase from X-ray diffraction data (see Table I). The earliest work by Carlsson et al. ${ }^{24}$ described the crystal structure with a trigonal $P \overline{3} 1 \mathrm{~m}$ space group. Later, based on the same type of unit cell, Brandon et al. ${ }^{25}$ and Lenz et al. $^{26}$ obtained two similar structure models, respectively. These models show a different atomic ordering than proposed in. ${ }^{24}$ While Lenz et al. ${ }^{26}$ used a $P 6_{3} / m$ space group, Brandon et al. ${ }^{25}$ obtained, upon structure refinement, slightly better fits to X-ray intensity data using a lower-symmetry $P 6_{3}$ description.

Against this background, in the present work, the phase evolution at the contact area of $\mathrm{Cu}$ and $\mathrm{Cu}-\mathrm{Ni}$ alloys with $\mathrm{Sn}$ is studied in the temperature range from $473 \mathrm{~K}$ to $623 \mathrm{~K}$, i.e. above and below the melting temperature of Sn, revealing formation of $\zeta$ $(\mathrm{Cu}, \mathrm{Ni})_{10} \mathrm{Sn}_{3}$ at temperatures as low as $523 \mathrm{~K}$. 


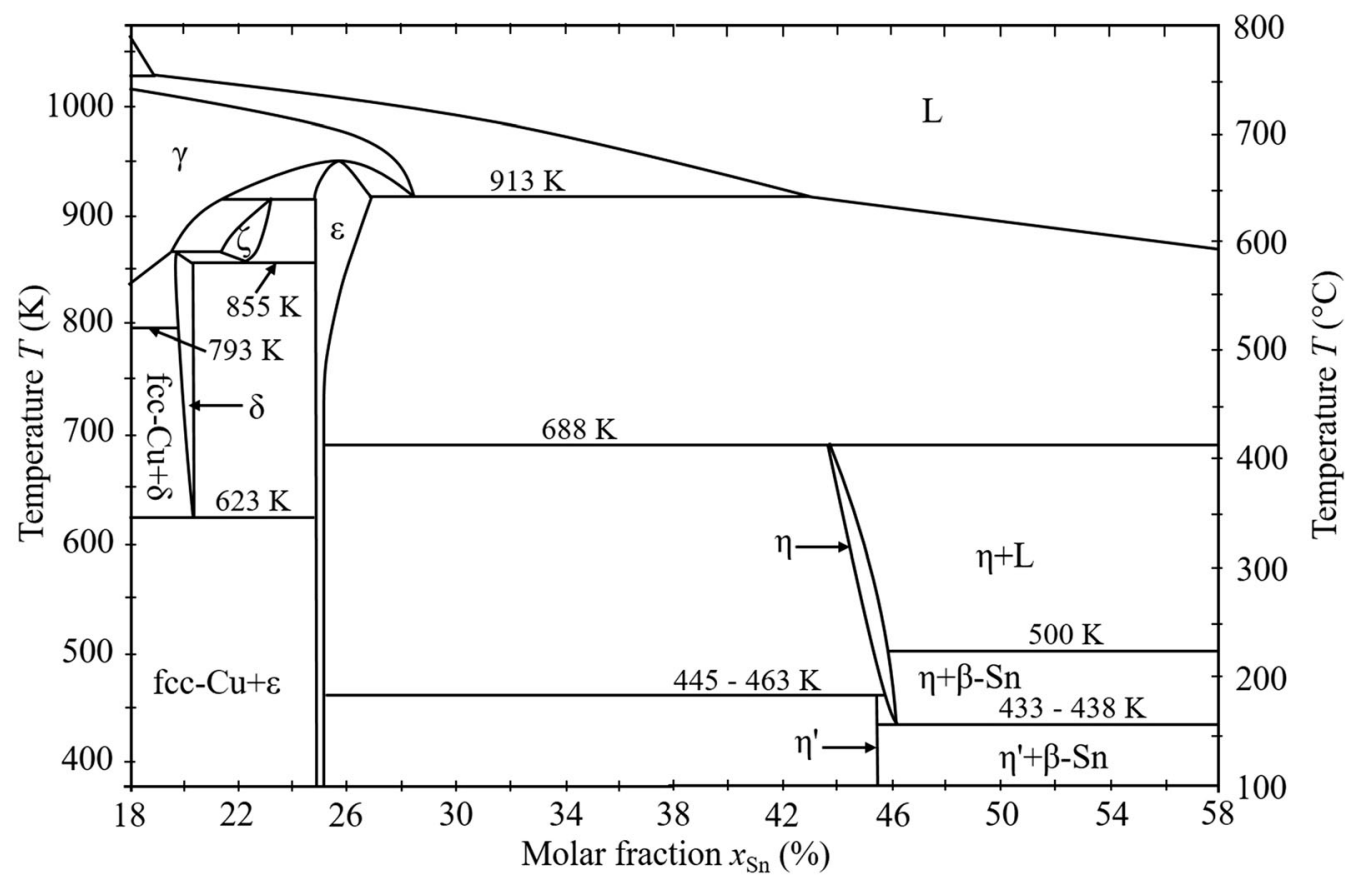

Fig. 1. Part of the binary Cu-Sn phase diagram redrawn after Saunders, ${ }^{17}$ including modifications concerning $\eta$ and $\eta^{\prime}$ phases in view of results from Wieser et al. ${ }^{21}$

\section{METHODS}

\section{Specimen Preparation}

Pure $\mathrm{Cu}$ plates with dimensions of $20 \times 10 \times$ $1 \mathrm{~mm}^{3}$ were cut out of a recrystallized pure $\mathrm{Cu}$ metal sheet $(99.99 \%$ metals basis, type K09, Wieland Werke AG). The different $\mathrm{Cu}-\mathrm{Ni}$ alloys containing 1 at.\% and 3 at.\% $\mathrm{Ni}$ were produced by arc melting, rolling and recrystallization for $1.5 \mathrm{~h}$. Finally, the stripes were cut into plates of dimensions $25 \times 10 \times 1 \mathrm{~mm}^{3}$.

All alloy plates were ground with $\mathrm{SiC}$ paper (final step $15 \mu \mathrm{m}$ grit size), polished (diamond suspension; particle size down $1 \mu \mathrm{m}$; Struers Tegra Pol-31; DiaDuo suspension) and subsequently cleaned, to ensure defined surface conditions. The resulting specimens were cleaned by standard industrial cleaning agents (Ronaclean, DOW Chemical and Descabase $\mathrm{Cu}$, Atotec) and coated with Sn layers with a thickness of $10 \mu \mathrm{m}(15 \mu \mathrm{m}$ for the specimens dedicated to the high annealing temperature of $573 \mathrm{~K}$ and $623 \mathrm{~K}$ ), which were electrodeposited from a ST200 electrolyte (DOW Chemical) using extruded tin counter anodes (99.9\% metals basis, BalverZinn). Electrodeposition was conducted with a current density of $6 \mathrm{~A} / \mathrm{dm}^{2}$ and a bath temperature of $313 \mathrm{~K}$.

The specimens dedicated for annealing at $473 \mathrm{~K}$ and $523 \mathrm{~K}$ were sealed under Ar in small, reusable polytetrafluoroethylene (PTFE) containers. The specimens for annealing at $573 \mathrm{~K}$ and $623 \mathrm{~K}$ were sealed under Ar in fused silica tubes. All specimens were annealed in a box furnace with an additional thermocouple placed next to the specimen container for the purpose of precise temperature monitoring. Annealing was terminated by quenching in ice water including an opening of the containers or tubes, directly after contact with ice water. This procedure ensures an efficient quenching of the specimen by immediate contact with the water. All the heat treatments $(473 \mathrm{~K}, 523 \mathrm{~K}, 573 \mathrm{~K}, 623 \mathrm{~K})$ were performed for $18 \mathrm{~h}$ and they were always performed on two identical specimens on each applied temperature within one container or tube. One specimen was dedicated to microstructural investigation (SEM, EDS, EBSD), the other one to $\mathrm{X}$-ray diffraction.

\section{Microstructural Analysis}

For microstructural analysis, the specimens were embedded in an epoxy resin (Struers EpoFix), ground and polished (suspension with particle size down to $1 \mu \mathrm{m}$ ). Finally, to achieve better surface quality, the metallographic cross sections were ionetched and covered with a thin sputter-deposited layer of gold to ensure electrical conductivity of the whole surface (Gatan Model 682 Precision etching coating system). Scanning electron microscopy (SEM) measurements including energy dispersive $\mathrm{X}$-ray spectroscopy (EDS) were performed on a Carl Zeiss EVO60 (W cathode) equipped with an X-Max EDS system (Oxford Instruments).

Electron backscatter diffraction (EBSD) analysis was performed after additional polishing using a colloidal silica suspension (OP-S; Struers). Corresponding analysis was performed on a JEOL JSM$7800 \mathrm{~F}$ scanning electron microscope with an EDAX 
EBSD system equipped with a Hikari Elite Super camera.

\section{X-Ray Diffraction}

After quenching the specimens, those dedicated to the powder X-ray diffraction (PXRD) measurements were treated with a solution of ortho-nitrophenol $(0.35 \mathrm{~g}$ alongside with $0.50 \mathrm{~g} \mathrm{NaOH}$ in $100 \mathrm{ml}$ water; $20 \mathrm{~min}$ at $333 \mathrm{~K}$ ). This leach-off process of remaining Sn ensured well-detectable intensity of the X-rays diffracted from the intermetallic phases, without any absorption of the X-rays by a Sn top layer. Additionally, this process step avoids any possible reactive interaction between $\mathrm{Sn}$, the intermetallic phases and the substrate during storage at ambient temperature.

Two types of powder X-ray diffraction (PXRD) measurements were performed:

(1) Symmetric reflection measurements were performed on all specimens using a Bruker D8 ADVANCE diffractometer equipped with a Co tube. A quartz-crystal Johannson monochromator behind the tube provided monochromatic $\mathrm{Co}-\mathrm{K}_{\alpha 1}$ radiation, which was used in the primary beam and a LYNXEYE position-sensitive detector in the diffracted beam.

(2) In order to reveal the texture of the $\zeta$ phase in more detail, a Bruker D8 Discover diffractometer equipped with a $1 / 4$ Eulerian cradle, a $\mathrm{Cu}$ tube with a Ni filter and a polycap optic $(45 \mathrm{~mm})$ providing parallel beam geometry were used. $2 \theta$ scans were performed, respectively, at constant tilting angle $\chi$ of $0^{\circ}, 15^{\circ}$, $30^{\circ}$ and $50^{\circ}$.

All diffraction data were evaluated using the software TOPAS. ${ }^{35}$ The peak profiles were modeled by a modified Thompson-Cox-Hastings pseudo-Voigt profile function as implemented in the TOPAS software. $^{36}$ Pawley fits ${ }^{37}$ were employed instead of conventional Rietveld fits due to very pronounced preferred orientation of most crystal phases. This allowed us to extract reflection intensities and lattice parameters. Pawley fits involve a large number of independent refined parameters, especially a refined integrated intensity value for each symmetry-independent reflection, which are predicted to occur on basis of the unit cell and the space group. The Pawley fits were performed based on the crystallographic data listed in Table I. Due to the low Laue symmetry of the $P 6_{3}$ and $P 6_{3} / \mathrm{m}$ models, Pawley refinements generate for many reflections independent reflections at exactly the same reflection position. To reduce the number of refined intensities, $P 6_{3} 22$ symmetry $(6 / \mathrm{mmm}$ Laue symmetry) was adopted for the Pawley refinements, because the intensities of the reflections encountered at the same positions cannot be determined independently.** In the case of using the simple Knoedler ${ }^{29}$ model for the $\varepsilon$ phase, the positions of a few superstructure reflections were not adequately reproduced. This was caused by the effect of antiphase boundaries on superstructure reflection positions. The positions of the superstructure reflections and also of the fundamental reflections were well accounted for in the model by Mueller and Lidin $^{31}$ contained in Table I. Thereby, additionally, the metric of $\varepsilon-\mathrm{Cu}_{3} \mathrm{Sn}$ was constrained to be pseudohexagonal by requiring $a / 2=b /\left(8 \times 3^{1 / 2}\right)$. Due to the large number of independent reflections implied by this structure model, which are typically all refined separately during a Pawley refinement, only wellobservable reflections were allowed to have non-zero intensity.

In order to highlight the important features in the measured diffraction pattern and the calculated intensities resulting from the fits, only a $2 \theta$ range from $20^{\circ}$ to $100^{\circ}$ is shown in all graphs in this manuscript, although all evaluations were done on the larger range from $20^{\circ}$ to $120^{\circ}$ and, thus, the reported parameters pertain to that range. The $R_{w p}$ and $G O F$ values are in a reasonable range, but they are not relevant for the discussed results in this manuscript and, therefore, are not listed in the following.

\section{RESULTS AND DISCUSSION}

For lowest annealing temperature of $473 \mathrm{~K}$ the thickness of the deposited Sn layer was always sufficient to retain a finite reservoir of elemental Sn after the heat treatment (Fig. 2a, b, and c). For $523 \mathrm{~K}$, only the specimen with the $\mathrm{Cu}-1$ at.\% $\mathrm{Ni}$ substrate material still shows at some areas, where due to the melting process Sn has agglomerated, remaining $\mathrm{Sn}$ at the surface (such an area is not shown in Fig. 2e), while the others do not (Fig. 2d, e, and $\mathrm{f}$ ). For the higher annealing temperatures $(573 \mathrm{~K}$ and $623 \mathrm{~K})$ no Sn layer is left at any specimen (Fig. 2g, h, i, j, k, and l).

Depending on the substrate material and the annealing temperature, different intermetallic phases were observed, which will be discussed in this chapter. At $473 \mathrm{~K} 3$ at. $\% \mathrm{Ni}$ in the substrate material were sufficient to suppress the formation of the $\varepsilon$ phase, while at $523 \mathrm{~K}$ using a $\mathrm{Cu}-1$ at.\% $\mathrm{Ni}$ substrate material, the $\zeta$ phase could be

\footnotetext{
**Reflections with the (Miller-Bravais) indices $h k(i) l$ and $k h(i) l$ occurring at the same diffraction angle $2 \theta$ due to Eq. (2) and Bragg's law, and also having the same $\varphi$ angle (see Eq. (1)), are generally nonequivalent reflections for the Laue group $6 / m$, i.e. the planes are not related by a symmetry operation (except for $h$, $k$ or $i=0$ or a pair of $h, k$ or $i$ being equal). These reflections are equivalent for Laue group 6/ $\mathrm{mmm}$. Separately refined intensities of this type of reflection are fully correlated in a Pawley refinement and have the same effect on the refinement result. In the TOPAS software the refinement algorithm suppresses the correlations; nevertheless, the intensities cannot be determined independently.
} 


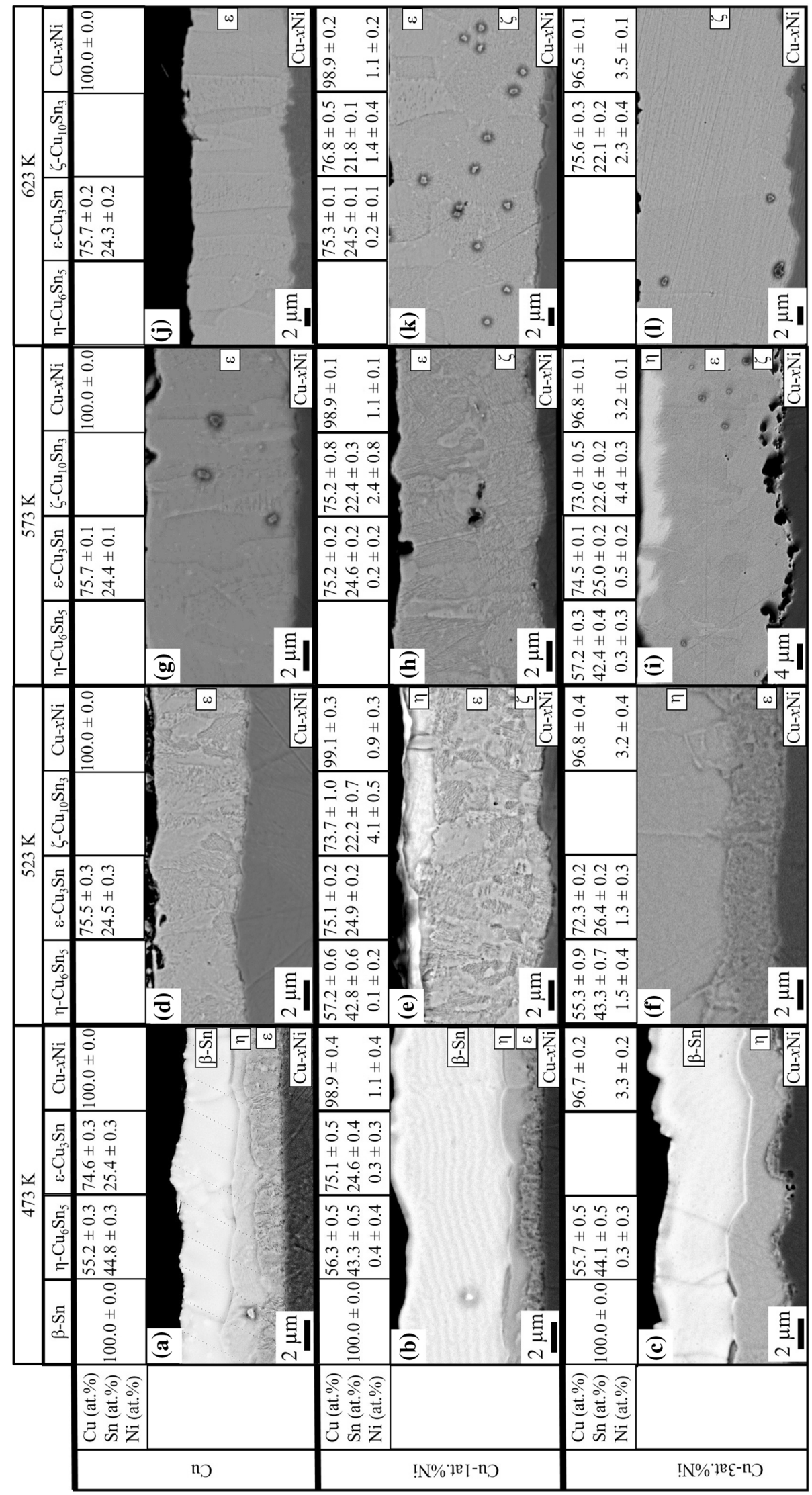

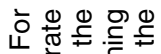

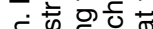

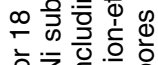

흔 $\bar{z}_{0} .0 .0$

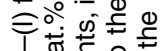

당

Х守它

लำ

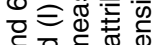

다을

$\widehat{=} \stackrel{0}{0} \stackrel{0}{\infty}$

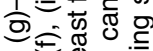

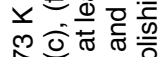

的

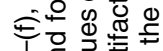

흥후

준 웅 등

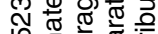

政

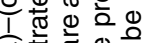

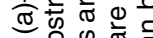

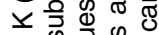

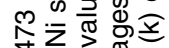

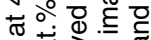

후 $\frac{\pi}{\sigma}$

元 0.

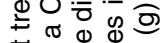

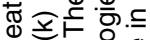

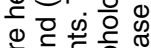

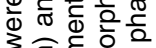

드의.

过要

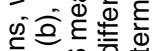

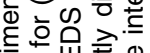

过出券

की

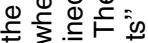

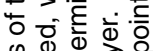

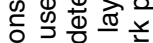

은 $\begin{aligned} & 3 \\ & 0\end{aligned}$

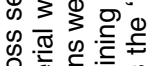

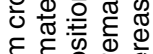

으

क

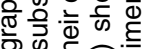

क क

엉응 응

응

후워

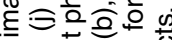

힝 뭉

응

ब.

के

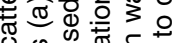

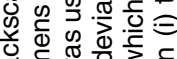

\%

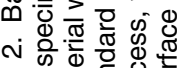

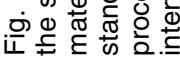


experimentally observed for the first time at this temperature. For higher annealing temperatures of $573 \mathrm{~K}$ and $623 \mathrm{~K}$, the $\zeta$ phase was observed for the $\mathrm{Cu}-1$ at. $\% \mathrm{Ni}$, as well as for the $\mathrm{Cu}-3$ at.\% $\mathrm{Ni}$ specimen in a large fraction. Because of this, a detailed characterization of this phase was possible and a strong $00 l$ texture for the $\zeta$ phase was revealed. In the following sections, the basic observations for the specimens annealed at the different temperatures are reported, the texture of the $\zeta$ phase is assessed and the results of EBSD measurements are reported.

\section{Phase Formation at $473 \mathrm{~K}$}

At $473 \mathrm{~K}$, Sn is solid, in contrast to the higher annealing temperatures. Hence, the intermetallic phases only form due to solid-state diffusion. The $\eta$ and $\varepsilon$ intermetallic phases have developed as uniform layers on the $\mathrm{Cu}$ substrate (see Fig. 2a). It can be seen that the $\eta$ phase initially grew along the grain boundaries of the $\mathrm{Sn}^{16,34}$ and the thickness of the $\varepsilon$ layer exceeded that of $\eta$. For the $\mathrm{Cu}-1$ at.\% $\mathrm{Ni}$ substrate, again both intermetallic phases develop (Fig. 2b), leading, however, to a much thinner $\varepsilon$ layer. Hence, Ni slows down the growth rate of the $\varepsilon$ phase but does not fully suppress its formation. This is consistent with the literature. ${ }^{4,5}$ Research dealing with the effect of preventing the growth of the $\varepsilon$ phase by introducing $\mathrm{Ni}$ from the Sn-rich side (e.g. solder paste), ${ }^{38}$ seemingly showed that 0.05 at. $\% \mathrm{Ni}$ are sufficient to suppress the formation of the $\varepsilon$ phase.

For the Cu-3at.\%Ni alloy (Fig. 2c), the formation of the $\varepsilon$ phase was totally suppressed. Furthermore, the $\eta$ layer was thicker than for the other two alloys. Hence, a Ni content of around 3 at.\% in the substrate material seems to be sufficient to suppress the formation of $\varepsilon$ phase under the described conditions, if the temperature is below the melting point of Sn. Also this observation is consistent with the literature. ${ }^{4-7}$

The evaluation of the EDS measurements (Fig. 2$a, b$, and c) shows that no considerable differences in the compositions of the intermetallic phases can be observed for the different specimens. The specimens with Ni-containing substrate possibly have a very small portion of $\mathrm{Ni}$ in the intermetallic phases. Based on the standard deviation and due to the spatial resolution of the electron probe of the EDS measurement, these results should be handled with caution. Nevertheless, as it was explained in the literature, $\mathrm{Ni}$ can be dissolved in the $\eta$ phase and appears to preferentially occupy $\mathrm{Cu}(2)$ sites (see Table I) and, therefore, substitute $\mathrm{Cu}$ atoms in the system. ${ }^{39}$ However, the $\mathrm{Cu}-3$ at. $\% \mathrm{Ni}$ specimens shows seemingly at the interface between substrate and $\eta$ phase an additional thin layer, which is regarded as $\mathrm{Ni}$ enriched $\eta-(\mathrm{Cu}, \mathrm{Ni})_{6} \mathrm{Sn}_{5}$ with some (Kirkendall) porosity. This implies a concentration gradient of $\mathrm{Ni}$ in the $\eta$ phase, like it is also detectable for the same substrate material annealed at $523 \mathrm{~K}$ (see section "Phase Formation at $523 \mathrm{~K}$ and at $573 \mathrm{~K}$ ").

The PXRD measurements of the three specimens show results, which are compatible with the evidence from SEM/EDS analysis. No evidence for the $\varepsilon$ phase was found in the $\mathrm{Cu}-3 \mathrm{at} . \% \mathrm{Ni}$ specimen, hence confirming that 3 at.\% $\mathrm{Ni}$ are sufficient to suppress the growth of the $\varepsilon$ phase completely.

\section{Phase Formation at $523 \mathrm{~K}$ and at $573 \mathrm{~K}$}

A higher annealing temperature of $523 \mathrm{~K}$, i.e. slightly above the melting temperature of $\mathrm{Sn}$, is necessary for soldering, implicating much higher mobility of the atoms. In particular, liquid Sn leads to a faster formation of the intermetallic phases.

For the specimen with $\mathrm{Cu}$ substrate (Fig. 2d), the intermetallic phase is mainly the $\varepsilon$ phase. Most of the $\eta$ phase was consumed by the $\varepsilon$ phase due to the lack of $\mathrm{Sn}$ and an excess of $\mathrm{Cu}$. The PXRD measurement (Fig. 3a) indicates that small fractions of $\eta$ are still present and additionally $\mathrm{Cu}$ substrate material is only partly detectable due to the strong absorption of the thick intermetallic layer.

In contrast, the specimen obtained from a $\mathrm{Cu}-$ 1at.\% $\mathrm{Ni}$ substrate shows a remaining thin layer of the $\eta$ phase (Fig. 2e). The growth of the $\varepsilon$ phase is sluggish due to the presence of $\mathrm{Ni}$. This can explain the remaining $\eta$ layer. An unexpected observation is an additional layer located between the substrate and the $\varepsilon$ phase. EDS measurements reveal a composition of 73.7 at. $\% \mathrm{Cu}, 22.2$ at. $\%$ Sn and 4.1 at.\% Ni (Fig. 2e). The Sn content is significantly lower than in the $\varepsilon$ phase and well compatible with the formula $\zeta-(\mathrm{Cu}, \mathrm{Ni})_{10} \mathrm{Sn}_{3}$, implying substitution of $\mathrm{Cu}$ by $\mathrm{Ni}$, suggesting that the layer is a Ni-stabilized $\zeta$ phase. The presence of the $\zeta$ phase is in particular confirmed by the PXRD data (Fig. 3b), showing two reflections attributable to the 113 and 006 reflections of the $\zeta$ phase (apart from reflections due to the substrate, $\eta$ and $\varepsilon$ ).

No $\zeta$ sublayer was observed for the specimen with the $\mathrm{Cu}-3$ at. $\% \mathrm{Ni}$ substrate (Figs. $2 \mathrm{f}$ and $3 \mathrm{c}$ ). Temperatures above the melting point of Sn and the lack of a remaining Sn reservoir seemingly lead to a formation of an $\varepsilon$ layer, which was suppressed by the $\mathrm{Ni}$ at lower temperatures (see section "Phase Formation at 473 K"). EDS measurements indicate the presence of some $\mathrm{Ni}$ in $\eta$ and $\varepsilon$ phase, if the measurement is close to the interface to the substrate material. This time the Sn content indicates the presence of the $\varepsilon$ phase (Fig. 2f) with a maximum $\mathrm{Ni}$ content of around 1 at.\%.

Annealing at $573 \mathrm{~K}$ leads to similar results compared to $523 \mathrm{~K}$. The specimen obtained from the $\mathrm{Cu}$ substrate consists predominantly of the $\varepsilon$ phase (Fig. 2g), including some remainders of the $\eta$ phase at some locations of the specimen (Fig. 4a). For Cu1 at. $\% \mathrm{Ni}$ the $\zeta$ phase is again visible in the EDS results (Fig. 2h) and in the PXRD pattern (Fig. 4b). For the specimen produced from $\mathrm{Cu}-3 \mathrm{at} . \% \mathrm{Ni}$, the 


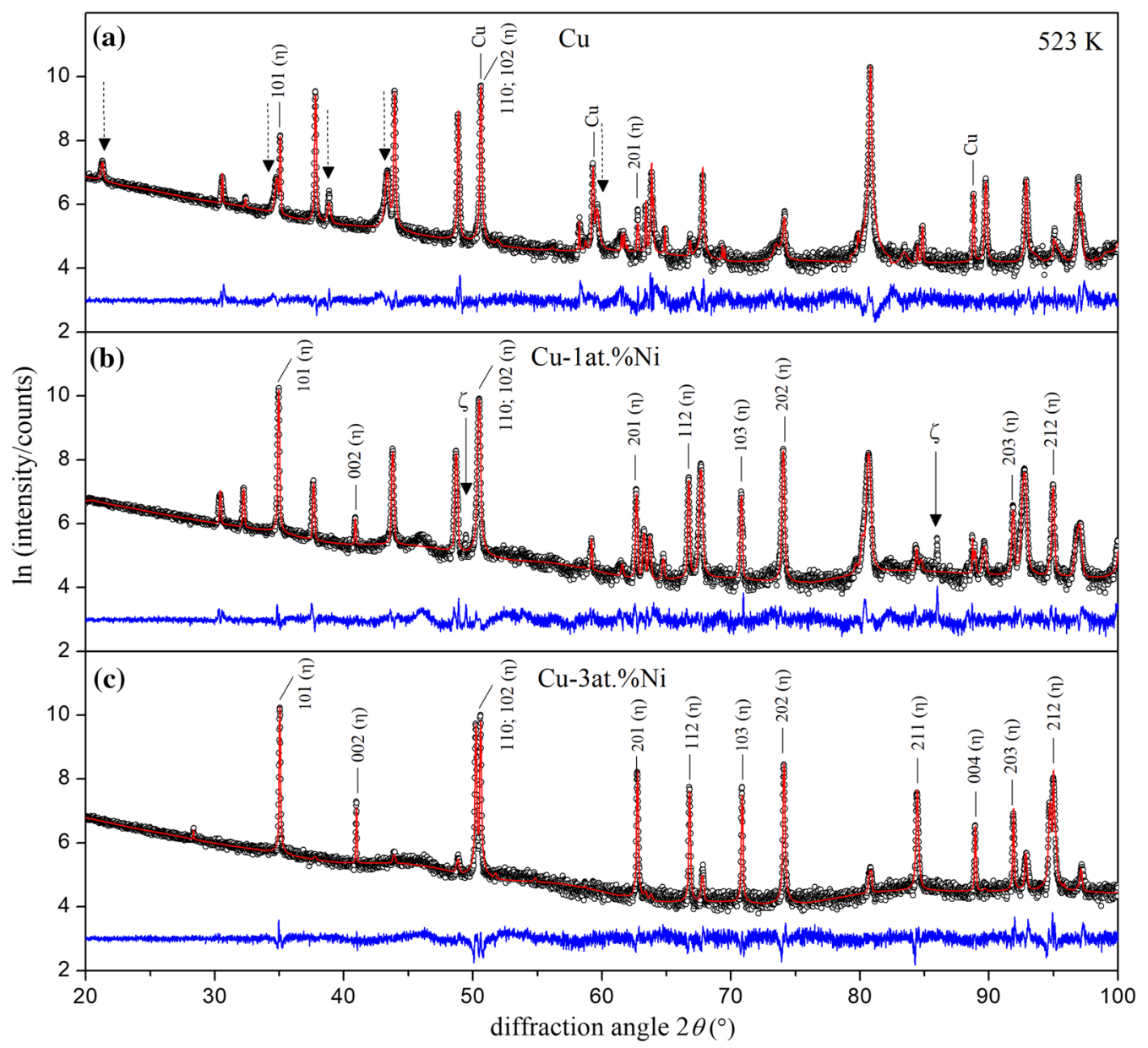

Fig. 3. X-ray diffraction data recorded using Co-K $\alpha_{1}$ radiation from specimens with (a) pure $\mathrm{Cu}$, (b) $\mathrm{Cu}-1$ at.\%Ni and (c) Cu-3at.\%Ni substrate material are indicated as black data points. The specimens were heat treated at $523 \mathrm{~K}$ for $18 \mathrm{~h}$. The calculated intensity considering $\mathrm{Cu}_{\mathrm{u}} \varepsilon-\mathrm{Cu}_{3} \mathrm{Sn}$, $\eta-\mathrm{Cu}_{6} \mathrm{Sn}_{5}$ and $\mathrm{SnO}$ (Pawley fit) is shown in red. The difference curves between measurement and refinement are shown in blue at the bottom. The dotted arrows in (a) indicate the reflections, which pertain to $\mathrm{SnO}$ and the reflections marked by drawn through arrows in (b) can be assigned to the $\zeta$ phase. The visible reflections of the $\mathrm{Cu}$ and the $\eta$ phase are indexed with the corresponding hkls. All other reflections correspond to the $\varepsilon$ phase.

PXRD data does not show reflections of the $\zeta$ phase (Fig. 4c). Nevertheless, SEM/EDS measurements reveal presence of a $\zeta$ layer next to the substrate (Fig. 2i), which, however, seems to be interrupted, in particular, at positions of enhanced void density (Kirkendall voids). Non-detection of the $\zeta$ phase by PXRD can thus be attributed to the thick $\varepsilon$ layer adjacent to the surfaces and a possibly small amount of $\zeta$ layer.

\section{Phase Formation at $623 \mathrm{~K}$}

EDS measurements indicate the sole presence of the $\varepsilon$ phase in the intermetallic layer of the specimen with the $\mathrm{Cu}$ substrate (Fig. 2j), whereas the PXRD results (Fig. 5a) show again small fractions of $\eta$ and $\mathrm{Cu}$, for the same reason as already discussed for the specimen annealed at $573 \mathrm{~K}$ or even $523 \mathrm{~K}$ (see section "Phase Formation at $523 \mathrm{~K}$ and at $573 \mathrm{~K}$ ").

For the $\mathrm{Cu}-1$ at.\% Ni substrate, although there is no significant change in contrast of the SEM image
(BSE contrast), the mean composition changes from 75.3 at. $\% \mathrm{Cu}, 24.5$ at.\% $\mathrm{Sn}$ and 0.2 at.\% $\mathrm{Ni}$ in the outer part of the intermetallic towards higher $\mathrm{Cu}$ content (76.8 at.\%), lower Sn content (21.8 at.\%) and appreciable higher $\mathrm{Ni}$ content (1.4 at.\%), which again indicates the presence of the $\varepsilon$ and $\zeta$ phase (Fig. 2k). Due to the relatively thick $\zeta$ layer, many reflections attributable to this phase are now well detectable in the PXRD pattern (Fig. 5b).

For the $\mathrm{Cu}-3 \mathrm{at} . \% \mathrm{Ni}$ specimen, the distribution of $\mathrm{Cu}, \mathrm{Ni}$ and $\mathrm{Sn}$ is over the whole intermetallic layer constant and fits the Sn content expected for the $\zeta$ phase (Fig. 2l). The PXRD results (Fig. 5c) correspond to this, showing additionally a few lowintensity reflections of the $\varepsilon$ phase. The same reflections occur for the $\zeta$ phase, as in the $\mathrm{Cu}$ 1 at. $\% \mathrm{Ni}$ specimen. Overall, within this specimen the occurrence of the $\zeta$ phase could be also proven for that substrate material by PXRD and due to its large $\zeta$ fraction it is suitable to analyze the 


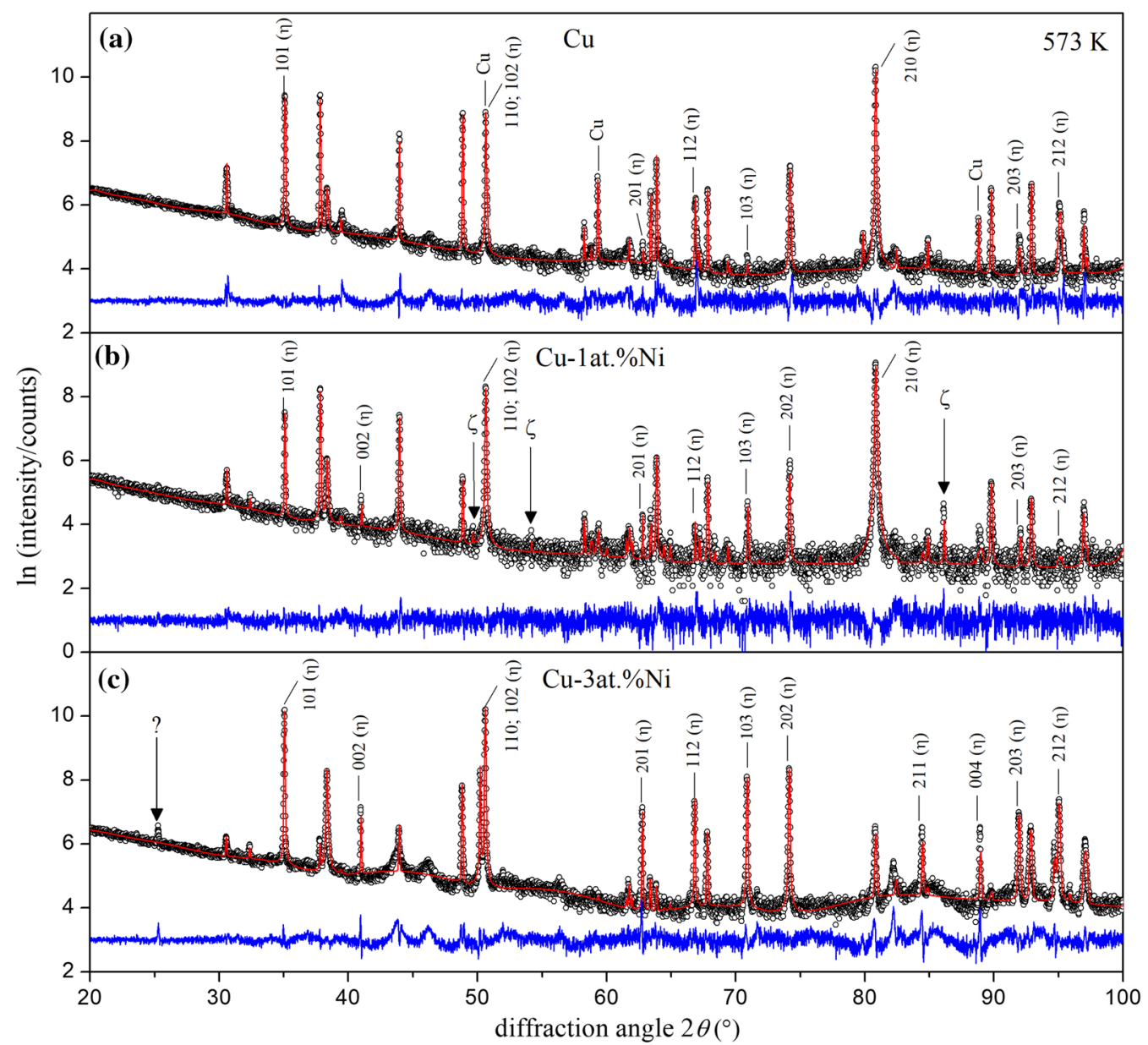

Fig. 4. X-ray diffraction data recorded using $\mathrm{Co}-\mathrm{K} \alpha_{1}$ radiation from specimens with (a) pure $\mathrm{Cu}$, (b) $\mathrm{Cu}-1$ at.\%Ni and (c) Cu-3at.\%Ni substrate material are indicated as black data points. The specimens were heat treated at $573 \mathrm{~K}$ for $18 \mathrm{~h}$. The calculated intensity, considering Cu, $\varepsilon^{-}$ $\mathrm{Cu}_{3} \mathrm{Sn}, \eta-\mathrm{Cu}_{6} \mathrm{Sn}_{5}$ and $\zeta-\mathrm{Cu}_{10} \mathrm{Sn}_{3}$ (Pawley fit) is shown in red. The difference curves between measurement and refinement are shown in blue at the bottom. The arrows in (b) indicate the reflections, which can be assigned to the $\zeta$ phase, whereas the arrow in (c) indicates a reflection which could not be fitted using any reference from Table I. The visible reflections of the $\mathrm{Cu}$ and the $\eta$ phase are indexed with the corresponding $h k / s$. All unmarked reflections correspond to the $\varepsilon$ phase.

microstructure of this phase in more detail, see following sections "Assessment of the Texture of the $\zeta$ Phase" and "Evaluation of the Electron Backscattered Diffraction Measurements".

\section{Assessment of the Texture of the $\zeta$ Phase}

The relative intensities of the reflections due to the $\zeta$ phase strongly deviated from the intensities expected from a random polycrystal according to the structure model of Ref. 25 Instead, the observed reflections typically have a large $l$ component, suggesting immediately a pronounced $00 l$ texture. This observation is confirmed here by further PXRD experiments involving specimen tilting away from the symmetry reflection geometry.

Figure 6 shows the results for the tilting angles $\chi=0^{\circ}, 15^{\circ}, 30^{\circ}$ and $50^{\circ}$. The reflections with the small intensities, which are not indexed with a $h k l$ reflection, can be attributed to the $\eta$ and $\varepsilon$ phase. The reflection marked with an arrow in Fig. $6 \mathrm{~d}$ cannot be attributed to one of these phases. Similar reflections were visible in Fig. 5 .

At $\chi=0^{\circ}$, the pronounced preferred orientation of the $\zeta$ phase with $00 l$ planes aligned preferentially parallel to the surface of the specimen becomes evident (Fig. 6a), as already shown in Fig. 5b and 5c and assumed in Figs. $3 \mathrm{~b}$ and $4 \mathrm{~b}: 00 \mathrm{l}$ reflections and such with large $l$ and small $h, k$ components have the largest intensities. These reflections are still strong for $\chi=15^{\circ}$, but additional reflections become visible. For the higher $\chi$ angles $\left(30^{\circ}\right.$ and $\left.50^{\circ}\right)$ none of the $00 l$ reflections are visible anymore.

In view of the $00 l$ texture concluded from the symmetric PXRD, it is possible to predict the reflections visible at a tilting angle $\chi$ on the basis of knowledge of the angle $\varphi$ between the reciprocal lattice vector of a reflection $h k l$ and the [001] direction. In case of an ideal $00 l$ (fiber) texture and perfect diffraction conditions, the reflection $h k l$ should appear at $\chi=\varphi$. For non-perfect texture 


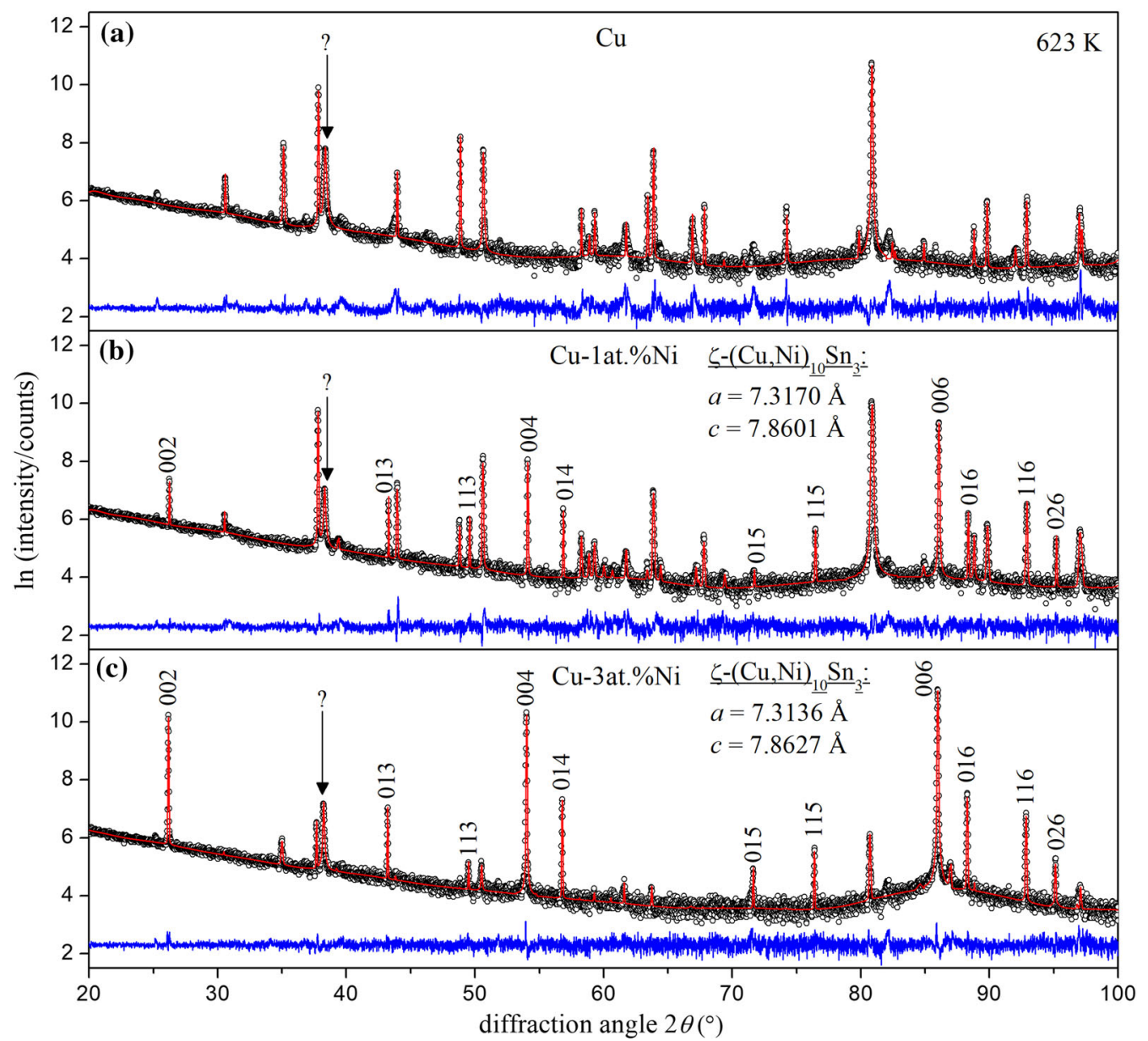

Fig. 5. Powder X-ray diffraction data recorded using Co-K $\alpha_{1}$ radiation from specimens with (a) pure $\mathrm{Cu}$, (b) Cu-1at.\%Ni and (c) Cu-3at.\%Ni substrate material are indicated as black data points. The specimens were heat treated at $623 \mathrm{~K}$ for $18 \mathrm{~h}$. The calculated intensity considering $\mathrm{Cu}, \varepsilon-\mathrm{Cu}_{3} \mathrm{Sn}, \eta-\mathrm{Cu}_{6} \mathrm{Sn}_{5}$ and $\zeta-\mathrm{Cu}_{10} \mathrm{Sn}_{3}$ (Pawley fit) is shown in red. The difference curves between measurement and refinement are shown in blue at the bottom. The arrows indicate the reflections which could not be fitted using any reference from Table I and hence are fitted with single peak phases. The reflections belonging to the $\zeta$ phase are marked with the corresponding $h k l s$.

and non-perfect diffraction geometry, this condition will be relaxed to some extent, but the maximum intensity for such a reflection is expected to occur close to $\chi=\varphi$.

To calculate the corresponding $\varphi$ angle for each reflection expected to occur within the diffraction angle range of $0^{\circ}-120^{\circ}\left(\mathrm{Cu}-\mathrm{K}_{\alpha}\right.$ radiation), the $h k l$ triplet was generated utilizing the TOPAS software $^{35}$ using the lattice parameters $a=7.330 \AA$ and $c=7.864 \mathrm{~A}^{25}$ Using geometrical considerations based on the hexagonal structure of the $\zeta$ phase, $\varphi$ was calculated for each $h k l$ by

$$
\cos \varphi=\frac{l d_{h k l}}{c},
$$

were the $d$-spacing for the hexagonal $\zeta$ phase was calculated via

$$
\left(\frac{1}{d_{h k l}}\right)^{2}=\frac{4}{3} \frac{h^{2}+k^{2}+h k}{a^{2}}+\frac{l^{2}}{c^{2}} .
$$

In the case of powder diffraction, certain reflections non-equivalent by Laue symmetry $(6 / m$ in case of both $P 6_{3}{ }^{24}$ and $P 6_{3} / \mathrm{m}^{25}$ ) occur at exactly the same reflection position. Therefore, in the course of a Pawley refinement, two intensities pertaining to the same observable reflection have to be refined (see footnote** and section "Methods"). Hence, mainly to keep the reflection list short, the higher $P 6_{3} 22$ symmetry with the same unit cell was employed for the refinements. Upon performing Pawley fits for the different $\chi$ angles, only such reflections attributable to the $\zeta$ phase on the basis of their positions were allowed to have non-zero intensity, which had visible diffracted intensity and for which the calculated angle $\varphi$ does not deviate too strongly from the value $\chi$ for which the pattern was recorded. Therefore, it was found for the $\chi=0^{\circ}$ measurement that all detectable reflections have a $\varphi<25^{\circ}$. In any case, the most prominent ones were the $00 l$ reflections with $\varphi=0^{\circ}$. For $\chi=15^{\circ}$ reflection with a $\varphi$ angle between $0^{\circ}$ and $40^{\circ}$ occur in the observed diffraction pattern. For measurement with $\chi=30^{\circ}$ 


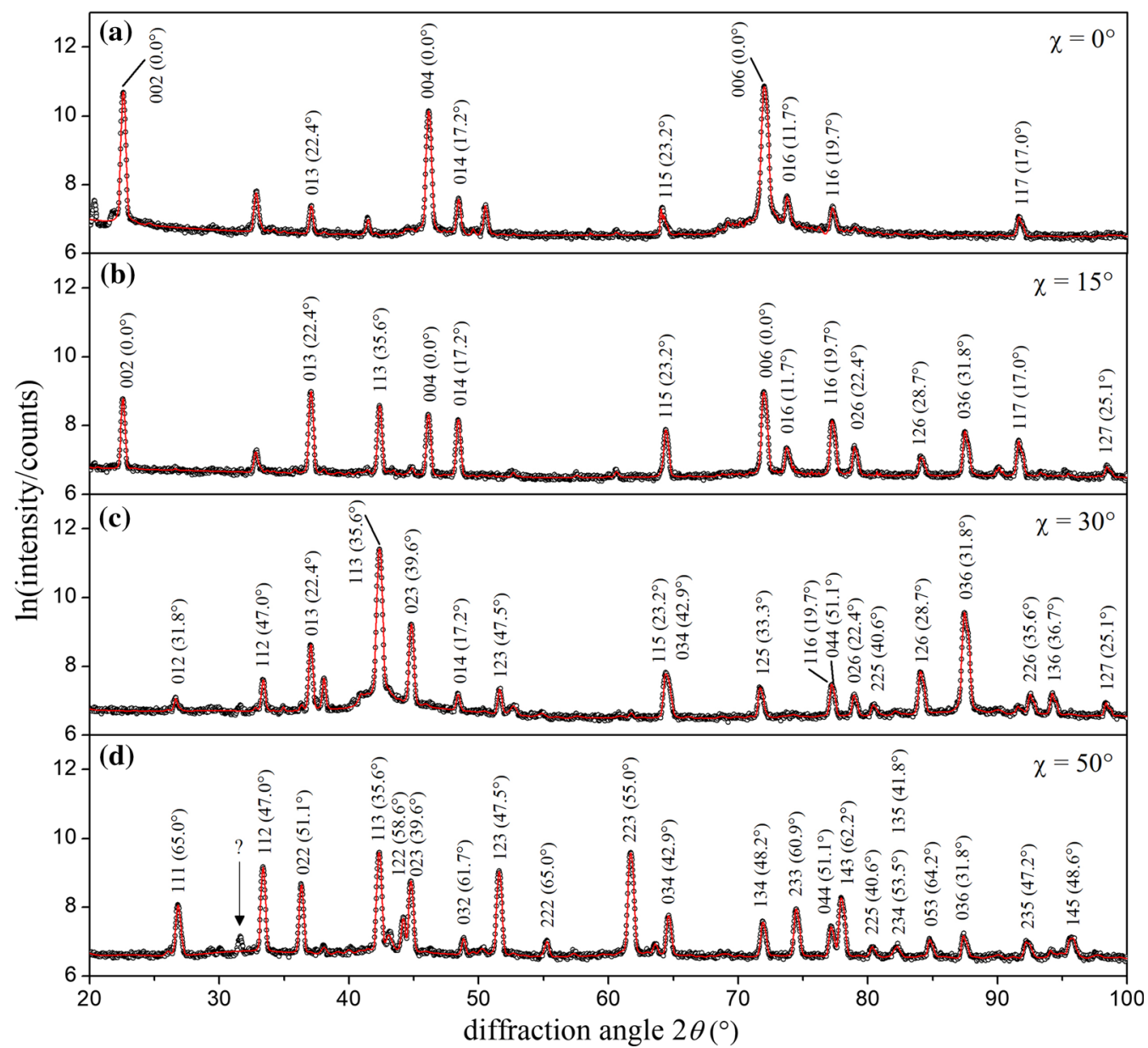

Fig. 6. X-ray diffraction data recorded using Cu radiation from a specimen with a Cu-3at.\%Ni substrate are indicated as black data points and calculated intensity curve (Pawley refinement) in red. The specimen was heat treated at $623 \mathrm{~K}$ for $18 \mathrm{~h}$. The calculated refinement curves, using $\zeta-\mathrm{Cu}_{10} \mathrm{Sn}_{3}$ are shown in red. Using an Eulerian cradle, an additional tilting with $\chi=0^{\circ}$ (a), $15^{\circ}$ (b), $30^{\circ}$ (c) and $50^{\circ}$ (d) was performed. The reflections were indexed with the corresponding $h \mathrm{kl}$ and the calculated $\varphi$ angle under which it should occur for an ideal texture [Eq (1)]. The nonindexed reflections belong to $\mathrm{Cu}, \varepsilon-\mathrm{Cu}_{3} \mathrm{Sn}$ and $\eta-\mathrm{Cu}_{6} \mathrm{Sn}_{5}$.

and $\chi=50^{\circ}, \varphi$ angles between $17^{\circ}-55^{\circ}$ and $32^{\circ}-65^{\circ}$ are encountered.

To validate whether the observed reflections correspond to the expected reflections for the $\zeta$ phase, reflection intensities expected for a random powder were calculated based on the reported crystal structure data. ${ }^{25}$ In Table II the reflections with the highest intensity from the single-crystal data are listed in the upper part, summing up possible nonequivalent reflections $h k l$ and $k h l$ (see footnote 2). A comparison of the four measurements displayed in Fig. 6 shows that strong reflections according to structure model are indeed observed, if $\varphi$ is sufficiently close to $\chi$.

\section{Evaluation of the Electron Backscattered Diffraction Measurements}

EBSD measurements were performed to further characterize the distribution of the $\zeta$ phase within the interdiffusion zone of intermetallic phases of different specimens. In order to avoid problems with pseudo-symmetry upon EBSD indexing, modified structure models were applied for the phases $\varepsilon^{-}$ $\mathrm{Cu}_{3} \mathrm{Sn}$ and $\zeta-\mathrm{Cu}_{10} \mathrm{Sn}_{3}$, basically by increasing the structures' symmetry. In the case of $\varepsilon$ - $\mathrm{Cu}_{3} \mathrm{Sn}$ the structure model variants, according to Ref. $29^{-31}$, are all derived from a hexagonally closed packed (hcp) arrangement of metal atoms, where the lattice parameters (in agreement with the present PXRD data) imply a very small orthorhombic distortion. Possible superstructure reflections of the structure models are neglected, as their intensity is so weak that they are most likely not detectable. Hence, for simplicity, reflectors generated by an average $h c p$ structure $\left(P 6_{3} / m m c\right.$ symmetry) and $a=2.76 \AA$ and $c=4.32 \AA$ were employed for indexing, thereby avoiding the need to distinguish between three virtually indistinguishable orientations. Specific atomic ordering phenomena were not taking into account, as the intensity of the detected Kikuchi bands are not evaluated. In the case of $\zeta-\mathrm{Cu}_{10} \mathrm{Sn}_{3}$ the relevant structure models $P 6_{3}$ (if only one chiral variant is considered ${ }^{24}$ ) and $P 6_{3} / \mathrm{m}^{25}$ are expected to generate Kikuchi patterns, where two different 
Table II. List of reflections of the $\zeta$ phase expected in a powder diffraction pattern $\left(\mathrm{CuK}_{\alpha}\right.$ radiation) with normalized intensities predicted for an untextured polycrystal ${ }^{25,35,40}$ with $\mathrm{hkls}, 2 \theta$ diffraction angles, and the $\varphi$ angles according to Eq. 1

\begin{tabular}{|c|c|c|c|c|c|c|c|}
\hline \multirow[b]{2}{*}{ hkl } & \multirow[b]{2}{*}{ Diffraction angle $2 \theta /{ }^{\circ}$} & \multirow[b]{2}{*}{ Intensity (normalized to 100) } & \multirow[b]{2}{*}{$\varphi /{ }^{\circ}$} & \multicolumn{4}{|c|}{ Observed at $\chi \chi^{\circ}$} \\
\hline & & & & $0^{\circ}$ & $15^{\circ}$ & $30^{\circ}$ & $50^{\circ}$ \\
\hline 110 & 24.26 & 6.4 & 90 & & & & \\
\hline 111 & 26.82 & 17.0 & 65.0 & & & & $\mathrm{x}$ \\
\hline 112 & 33.39 & 10.2 & 47.0 & & & $\mathrm{x}$ & $\mathrm{x}$ \\
\hline 202 & 36.35 & 6.2 & 51.1 & & & $\mathrm{x}$ & $\mathrm{x}$ \\
\hline $210 / 120$ & 37.45 & 6.7 & 90 & & & & \\
\hline $211 / 121$ & 39.22 & 5.5 & 73.0 & & & & \\
\hline 113 & 42.36 & 92.7 & 35.6 & & $\mathrm{x}$ & $\mathrm{x}$ & $\mathrm{x}$ \\
\hline 300 & 42.70 & 100.0 & 90 & & & & \\
\hline 203 & 44.80 & 14.8 & 39.6 & & $\mathrm{x}$ & $\mathrm{x}$ & $\mathrm{x}$ \\
\hline $213 / 123$ & 51.60 & 8.7 & 47.5 & & & $\mathrm{x}$ & $\mathrm{x}$ \\
\hline 223 & 61.71 & 21.5 & 55.0 & & & $\mathrm{x}$ & $\mathrm{x}$ \\
\hline $314 / 134$ & 71.93 & 4.9 & 48.2 & & & $\mathrm{x}$ & $\mathrm{x}$ \\
\hline $323 / 233$ & 74.47 & 7.6 & 60.9 & & & & $\mathrm{x}$ \\
\hline $413 / 143$ & 77.94 & 15.6 & 62.2 & & & & $\mathrm{x}$ \\
\hline 330 & 78.18 & 9.0 & 90 & & & & \\
\hline 306 & 87.47 & 13.4 & 31.8 & & $\mathrm{x}$ & $\mathrm{x}$ & $\mathrm{x}$ \\
\hline 336 & 119.07 & 6.2 & 47.0 & & & $\mathrm{x}$ & $\mathrm{x}$ \\
\hline 002 & 22.59 & 1.6 & 0 & $\mathrm{x}$ & $\mathrm{x}$ & & \\
\hline 103 & 37.07 & 4.5 & 22.4 & $\mathrm{x}$ & $\mathrm{x}$ & $\mathrm{x}$ & \\
\hline 004 & 46.13 & 1.6 & 0 & $\mathrm{x}$ & $\mathrm{x}$ & & \\
\hline 104 & 48.43 & 1.3 & 17.2 & $\mathrm{x}$ & $\mathrm{x}$ & $\mathrm{x}$ & \\
\hline 115 & 64.41 & 1.6 & 23.2 & $\mathrm{x}$ & $\mathrm{x}$ & $\mathrm{x}$ & \\
\hline 006 & 71.99 & 4.9 & 0 & $\mathrm{x}$ & $\mathrm{x}$ & & \\
\hline 106 & 73.75 & 0.5 & 11.7 & $\mathrm{x}$ & $\mathrm{x}$ & & \\
\hline 116 & 77.24 & 1.6 & 19.7 & $\mathrm{x}$ & $\mathrm{x}$ & $\mathrm{x}$ & \\
\hline 117 & 91.64 & 0.6 & 17.0 & $\mathrm{x}$ & $\mathrm{x}$ & & \\
\hline
\end{tabular}

Upper part: reflections with the normalized intensity $>5$ and lower part: reflections with planes with orientations close to (00l) with comparably low intensities. The crosses indicate which reflections are also visible in the X-ray diffraction data recorded from the specimen with a Cu-3at.\% Ni substrate material annealed at $623 \mathrm{~K}$ for $18 \mathrm{~h}$, with the different $\chi$ angles of $0^{\circ}, 15^{\circ}, 30^{\circ}$ and $50^{\circ}$
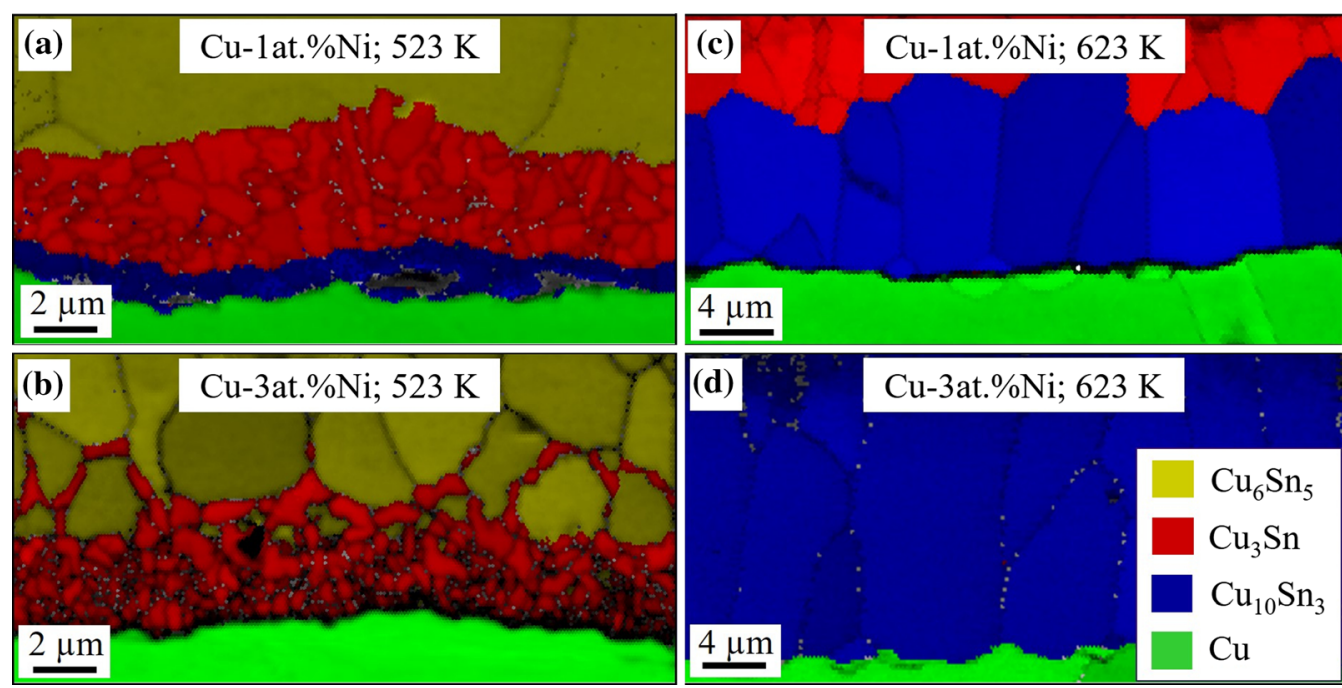

Fig. 7. EBSD phase maps of the cross sections of the intermetallic layers developed for the indicated specimens upon annealing for $18 \mathrm{~h}$ at the indicated temperatures: $\mathrm{Cu}$ (green), $\zeta-\mathrm{Cu}_{10} \mathrm{Sn}_{3}$ (blue), $\varepsilon-\mathrm{Cu}_{3} \mathrm{Sn}$ (red) and $\eta-\mathrm{Cu}_{6} \mathrm{Sn}_{5}$ (yellow) are indexed according the measured Kikuchi pattern. 


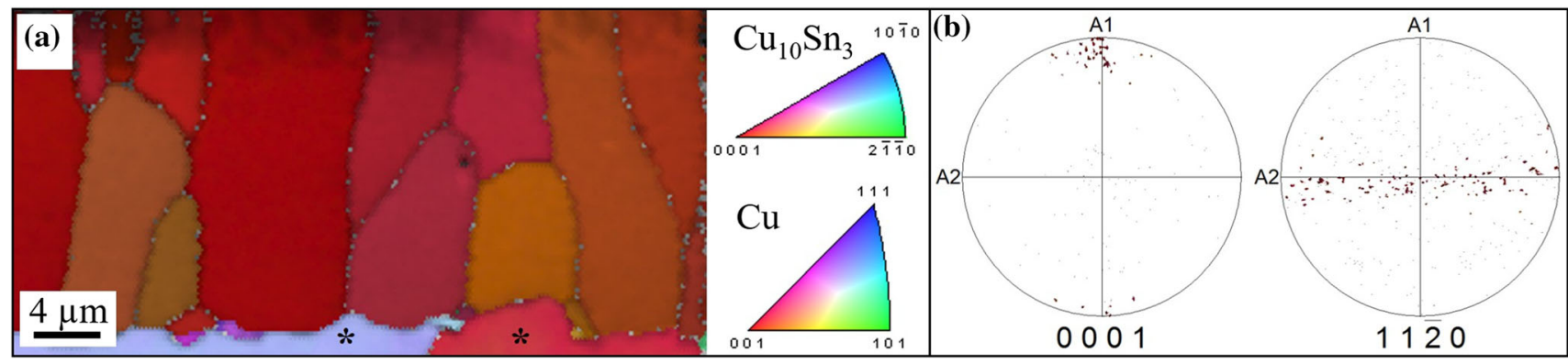

Fig. 8. EBSD measurement on a cross section of the intermetallic formed on the specimen with the Cu-3at.\%Ni substrate material annealed at $623 \mathrm{~K}$ for $18 \mathrm{~h}$; (a) shows the texture of the specimen with the corresponding color code referring to the vertical direction of the figure (corresponding to specimen normal the two grains marked with an asterisk are the substrate material) and (b) the density of the (00/) and (h00) pole of the $\zeta-(\mathrm{Cu}, \mathrm{Ni})_{10} \mathrm{Sn}_{3}$ phase for the map shown on the left side.

orientations can only be distinguished based on the minor intensity differences of pairs of $h k l / k h l$ bands. This problem is circumvented by employing for indexing strong reflectors pertaining to a unit cell of the same type of $a=7.330 \AA$ and $c=7.864 \AA$, but artificially imposing $6 / \mathrm{mmm}$ Laue symmetry, thus avoiding the need to distinguish between two virtually indistinguishable orientations. For the $\mathrm{Cu}^{27}$ and $\eta-\mathrm{Cu}_{6} \mathrm{Sn}_{5}$ phases $\left(a=4.19 \AA, c=5.09 \AA, P 6_{3} / m m c\right.$ symmetry and the atomic model described in footnote $b$ to Table I according to Ref. 34), reflectors for indexing were based on kinematically simulated Kikuchi band intensities. It is thereby possible to arrive at a robust distinction between the phases and to draw phase maps (Fig. 7) and achieve unspeckled inverse pole figure maps as exemplarily shown in Fig. 8.

The phase maps in Fig. 7 of selected specimens confirm the results concluded for the respective specimens by SEM/EDS supplemented by PXRD analysis. In the case of Fig. 7a, c indexing of the Kikuchi patterns clearly revealed a $\zeta$-phase layer, which was hardly discernible from $\varepsilon$ in the SEM image taken with BSE contrast (Fig. 2e, k). Moreover, absence of $\zeta$ phase in the case of the $\mathrm{Cu}$ $3 a t . \% \mathrm{Ni}$ specimen annealed at $523 \mathrm{~K}$ was confirmed (Fig. 7b), where over a certain thickness both $\eta$ and $\varepsilon$ appear to coexist. In the case of the specimen with the $\mathrm{Cu}-3$ at. $\% \mathrm{Ni}$ substrate material annealed at $623 \mathrm{~K}$ predominance of the $\zeta$ phase was confirmed (Fig. 7d).

The orientation information acquired in the course of the EBSD measurements confirm the $00 l$ texture already evidenced by the PXRD measurements (see Fig. 8).

\section{OVERALL DISCUSSION}

Non-occurrence of the $\zeta$ phase from a $\mathrm{Cu}$ substrate at the employed temperature complies with the $\mathrm{Cu}$-Sn phase diagram (Fig. 1). ${ }^{17,18,21}$ Contents of 1 at.\% $\mathrm{Ni}$ as well as 3 at.\% $\mathrm{Ni}$ in the substrate are sufficient to generate, under the current conditions (e.g. amounts of Sn present), the $\zeta$ phase at temperatures as low as $523 \mathrm{~K}$. Evidently, a certain $\mathrm{Ni}$ content is necessary to stabilize $\zeta-(\mathrm{Cu}, \mathrm{Ni})_{10} \mathrm{Sn}_{3}$ at these temperatures. The $\zeta$ phases in the specimens
$\mathrm{Cu}-1$ at. $\% \mathrm{Ni}$ at $523 \mathrm{~K}$ and $\mathrm{Cu}-3$ at. $\% \mathrm{Ni}$ at $573 \mathrm{~K}$ have an average $\mathrm{Ni}$ content of $4.1 \pm 0.5$ and $4.4 \pm 0.3$ at.\%, respectively. The larger $\zeta$ fractions in the samples obtained from $\mathrm{Cu}-1$ at. $\% \mathrm{Ni}$ at $573 \mathrm{~K}$, or alternatively from $\mathrm{Cu}-1$ at. $\% \mathrm{Ni}$ at $623 \mathrm{~K}$ and $\mathrm{Cu}$ 3 at. $\% \mathrm{Ni}$ at $623 \mathrm{~K}$ have an average $\mathrm{Ni}$ content of $2.4 \pm 0.8,1.4 \pm 0.4$ and $2.3 \pm 0.4$ at.\% (see Fig. 2). These composition data have been assembled in a Gibbs triangle for the Cu-Ni-Sn system (Fig. 9) and the particular data points are connected by lines with the substrate material's nominal composition (Cu-1at.\%Ni and $\mathrm{Cu}-3$ at.\%Ni). Assuming local equilibrium between substrate and the $\zeta$ phase, the connecting lines can be regarded as tie-lines crossing the two-phase field $\zeta+$ fcc-Cu solid solution. The tie lines indicate:

(a) The approximate Sn content in the $\zeta$ phase amounts to $21.8-22.6$ at.\%, which is only slightly smaller than 23.1 at.\% expected from the formula $(\mathrm{Cu}, \mathrm{Ni})_{10} \mathrm{Sn}_{3}$.

(b) At a given annealing temperature the $\mathrm{Ni}$ content determined for the $\zeta$ phase is higher for the $\mathrm{Cu}-3$ at. $\% \mathrm{Ni}$ than for the $\mathrm{Cu}-1$ at. $\% \mathrm{Ni}$ substrate material.

(c) For a given substrate composition, the $\mathrm{Ni}$ content in the $\zeta$ phase increases with $d e$ creasing temperature.

These findings may very well correspond to realistic phase equilibria between $\zeta+\mathrm{fcc}-\mathrm{Cu}$. At the relevant temperatures likely a tie-line triangle $\zeta+\varepsilon+\mathrm{fcc}-\mathrm{Cu}$ exists, with a low solubility of $\mathrm{Ni}$ in the $\varepsilon$ phase. This tie-line triangle has a $\zeta$-phase corner, which moves towards higher $\mathrm{Ni}$ contents with decreasing temperature.

Figure 9 also includes tie-lines from composition measurements from $\mathrm{Cu}-\mathrm{Ni}-\mathrm{Sn}$ bulk alloys equilibrated at $673 \mathrm{~K}^{23}$ These data indicate a high $\mathrm{Sn}$ content in the fcc solid solution, which is not evident from the current data: there is no sign for significant incorporation of $\mathrm{Sn}$ into the substrate material, see also EDS results in Fig. 2. This discrepancy can be attributed to the strongly temperature-dependent solvus of the fcc solid solution, at least in the 


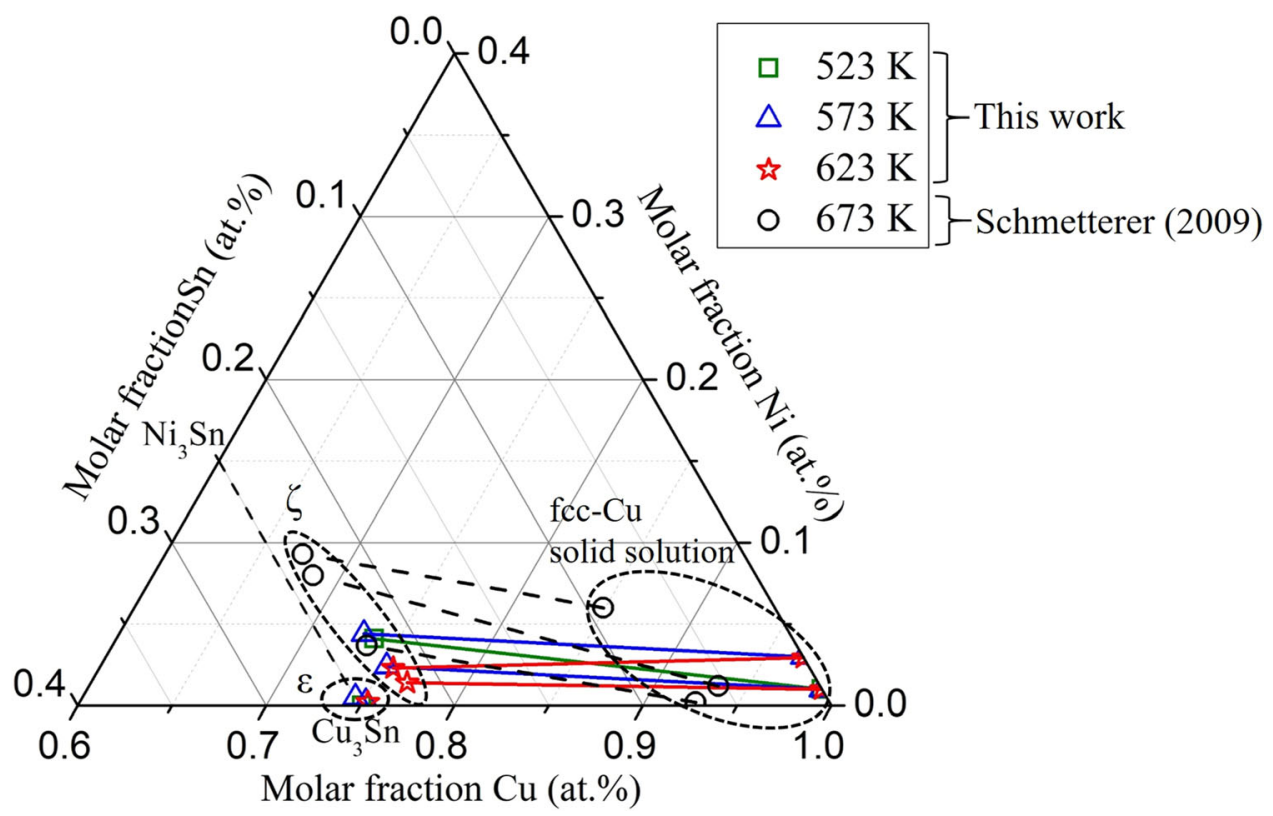

Fig. 9. Cu-rich section of the ternary Cu-Ni-Sn phase diagram. The compositions of $\varepsilon-\mathrm{Cu}_{3} \mathrm{Sn}$ and $\zeta-(\mathrm{Cu}, \mathrm{Ni})_{10} \mathrm{Sn}_{3}$ based on EDS measurements are indicated by squares $(523 \mathrm{~K})$, triangles $(573 \mathrm{~K})$ and asterisks $(623 \mathrm{~K})$. The corresponding data of Schmetterer et al. ${ }^{23}$ at $673 \mathrm{~K}$ are indicated by circles. The tie lines are shown by lines (this work) and dashed lines (Schmetterer et al. ${ }^{23}$ )

binary Cu-Sn system. ${ }^{17}$ Note the general difficulty to determine such solvus curves reliably at low temperatures. Moreover, the Ni contents of the $\zeta$ phase encountered in Ref. 23 are much higher than the presently determined values, leading to a crossing of the tie-lines from $623 \mathrm{~K}$ (present data) and $673 \mathrm{~K}{ }^{23}$ This is not forbidden for tie lines pertaining to different temperatures, but seems unlikely to this extent. Hence, although the observed trends (ac) listed above seem to be reasonable from a thermodynamic point of view, the quantitative composition data may be affected by non-local equilibrium for the present data.

The actual growth kinetics of the intermetallic phases in the investigated diffusion couples has not been the focus of the present work. Therefore, the complete consumption of the Sn layer upon intermetallic phase formation, as encountered for most of the present specimens, must be emphasized. This consumption implies that even in the case when the formation of the intermetallic phases is controlled by diffusion, the semi-infinite character of the diffusion couple in the sense of Ref. 41 makes the diffusion paths ${ }^{\dagger}$ non-invariant and the phase composition may change even beyond the consumption of Sn (and possibly of further Sn-rich phases like $\eta$ ). Consequently, individual phases like $\zeta_{-}(\mathrm{Cu}, \mathrm{Ni})_{10} \mathrm{Sn}_{3}$ might appear or disappear during the interdiffusion process. Therefore, the absence of the $\zeta$ phase for the specimen generated from $\mathrm{Cu}-3 a t . \% \mathrm{Sn}$ substrate (in contrast to $\mathrm{Cu}-1$ at.\%Sn) upon annealing for $18 \mathrm{~h}$ at

${ }^{\dagger}$ The diffusion path is the evolution of the laterally averaged composition in the diffusion layer.
$523 \mathrm{~K}$, might be the result of complicated processes related to the changes in the diffusion path. ${ }^{41}$ For this specimen, the region with coexistence of $\varepsilon+\eta$ (see Fig. 7b) is a typical feature allowed to occur for diffusion zones in ternary diffusion couples, whereas in binary couples such dual-phase layers are not permitted. ${ }^{41}$ In any case, the occurrence of the $\zeta$ phase will definitely influence the growth kinetics during soldering, and non-consideration of its possible occurrence may invalidate attempts to quantitatively model phase evolutions.

The pronounced texture encountered for the $\zeta$ phase in all cases in the present work hints e.g. to the anisotropic diffusion in a hexagonal crystal structure. Even if random $\zeta$ phase nuclei may initially be present, a much faster diffusivity along [001] than perpendicular would cause a texture observed like this.

Finally, it should be mentioned that stabilization of the $\zeta-\mathrm{Cu}_{10} \mathrm{Sn}_{3}$ phase by $X=\mathrm{Ni}$ as a third element is not unique among the $\mathrm{Cu}-\mathrm{Sn}-X$ systems, as e.g. $X=$ In has a similar effect of stabilizing the $\zeta$ phase towards lower temperatures. ${ }^{42,43}$ In substitutes Sn, i.e. leading to a formula $\mathrm{Cu}_{10}(\mathrm{Sn}, \mathrm{In})_{3}$. Common to the cases of $X=\mathrm{Ni}$ and $X=\mathrm{In}$ is that they provide one electron less than the substituted element $(\mathrm{Cu}$ and $\mathrm{Sn}$ ), indicating that the lowering of the electron concentration might be responsible for the energetic stabilization of the $\zeta$ phase.

\section{CONCLUSION}

The influence of $\mathrm{Ni}$, provided by $\mathrm{Cu}$-based substrate materials on the intermetallic phase formation upon reaction with $\mathrm{Sn}$, which is particularly 
relevant to the soldering process, was analyzed. The intermetallic phases were generated via $(\mathrm{Cu}-$ $x$ at. $\% \mathrm{Ni})-\mathrm{Sn}(x=1,3)$ diffusion couples annealed at $473 \mathrm{~K}, 523 \mathrm{~K}, 573 \mathrm{~K}$ and $623 \mathrm{~K}$, respectively. SEM/EDS, EBSD and PXRD data were the basis to characterize the intermetallic phases in the $\mathrm{Cu}-\mathrm{Ni}$ Sn system. Based on the measured results, following conclusions can be drawn:

(i) For the first time experimental evidence is presented that the formation of $\zeta-(\mathrm{Cu}$, $\mathrm{Ni})_{10} \mathrm{Sn}_{3}$ with about 4 at.\% $\mathrm{Ni}$ was encountered at $523 \mathrm{~K}$, i.e. at temperature relevant for liquid-phase soldering, whereas this phase is only stable down to $855 \mathrm{~K}$ in the binary $\mathrm{Cu}$-Sn system. Previous claims of Wachtel and Bayer $^{20}$ based on unclear experimental evidence are thereby confirmed, and experimental evidence from Schmetterer et al. ${ }^{23}$ going down to $673 \mathrm{~K}$ are extended considerably.

(ii) In SEM measurements the backscattered electron contrast between the $\varepsilon-\mathrm{Cu}_{3} \mathrm{Sn}$ and the $\zeta-(\mathrm{Cu}, \mathrm{Ni})_{10} \mathrm{Sn}_{3}$ phases is very weak, such that mutual presence of both phases is easily overlooked and can only be assessed reliably by means of further techniques, like electron backscatter diffraction.

(iii) The hexagonal $\zeta-(\mathrm{Cu}, \mathrm{Ni})_{10} \mathrm{Sn}_{3}$ shows a pronounced $00 l$ texture hinting at a preferred diffusion along the [001] crystallographic direction.

(iv) Possible development of the $\zeta$ phase in the presence of $\mathrm{Ni}$ should be considered upon evaluating microstructures forming during soldering und upon modelling phase growth kinetics. Moreover, the properties of the $\zeta$ phase and its potential influence on the reliability of solder joints, especially in the sense of so-called intermetallic compound cracks, should be investigated in more detail. Possible formation of the $\zeta$ phase should also be considered when it is tried to suppress the order-disorder transition of the $\mathrm{Cu}_{6} \mathrm{Sn}_{5}$ intermetallic by presence of $\mathrm{Ni}^{44}$

\section{ACKNOWLEDGEMENT}

Open Access funding provided by Projekt DEAL. The authors are thankful to Dr. Christian Schimpf (TU Freiberg) for performing the X-ray diffraction measurements.

\section{OPEN ACCESS}

This article is licensed under a Creative Commons Attribution 4.0 International License, which permits use, sharing, adaptation, distribution and reproduction in any medium or format, as long as you give appropriate credit to the original author(s) and the source, provide a link to the Creative Commons licence, and indicate if changes were made. The images or other third party material in this article are included in the article's Creative Commons licence, unless indicated otherwise in a credit line to the material. If material is not included in the article's Creative Commons licence and your intended use is not permitted by statutory regulation or exceeds the permitted use, you will need to obtain permission directly from the copyright holder. To view a copy of this licence, visit http://creativecom mons.org/licenses/by/4.0/.

\section{REFERENCES}

1. E.K. Ohriner, Weld. J. 7, 191 (1987).

2. T. Laurila, V. Vuorinen, and J. Kivilahti, Mater. Sci. Eng. 49, 1 (2005).

3. T. Laurila, V. Vuorinen, and M. Paulasto-Kröckel, Mater. Sci. Eng. 68, 1 (2010).

4. V. Vuorinen, T. Laurila, T. Mattila, E. Heikinheimo, and J.K. Kivilahti, J. Electron. Mater. 36, 1355 (2007).

5. V. Vuorinen, H. Yu, T. Laurila, and J.K. Kivilahti, J. Electron. Mater. 37, 792 (2008).

6. V. Baheti, S. Islam, P. Kumar, R. Ravi, R. Narayanan, D. Hongqun, V. Vuorinen, T. Laurila, and A. Paul, Philos. Mag. 96, 15 (2016).

7. V. Baheti, S. Kashyap, P. Kumar, K. Chattopadhyay, and A. Paul, J. Alloys Compd. 727, 832 (2017).

8. T. Maeshima, H. Ikehata, K. Terui, and Y. Sakamoto, Mater. Des. 103, 106 (2016)

9. T. Laurila and A. Paul, Crit. Rev. Solid State Mater. Sci. 41, 73 (2016).

10. K. Nogita, S.D. McDonald, H. Tsukamoto, J. Read, S. Suenaga, and T. Nishimura, Trans. Jpn. Inst. Electron. Packag. 2, 46 (2009).

11. D. Mu, J. Read, Y. Yang, and K. Nogita, J. Mater. Res. 26, 2660 (2011).

12. P. Yao, P. Liu, and J. Liu, J. Alloys Compd. 462, 73 (2008).

13. K. Nogita, Intermetallics 18, 145 (2010).

14. J. Xian, M. Mohd Salleh, S. Belyakov, T. Su, G. Zeng, K. Nogita, H. Yasuda, and C.M. Gourlay, Intermetallics 102, 34 (2018).

15. G. Zeng, S.D. McDonald, Q. Gu, Y. Terada, K. Uesugi, H. Yasuda, and K. Nogita, Acta Mater. 83, 357 (2015).

16. D.K. Mu, S.D. McDonald, J. Read, H. Huang, and K. Nogita, Curr. Opin. Solid State Mater. Sci. 20, 55 (2016).

17. N. Saunders and A.P. Miodownik, Bull. Alloy Phase Diagr. 3, 278 (1990).

18. S. Fuertauer, D. Li, D. Cupid, and H. Flandorfer, Intermetallics 34, 142 (2013).

19. Z. Wang and T. Konno, Philos. Mag. 93, 949 (2013).

20. E. Wachtel and E. Bayer, Z. Metallk. 75, 61 (1984).

21. C. Wieser, W. Huegel, A. Walnsch, and A. Leineweber, J. Electron. Mater. 49, 245 (2020).

22. G. Ghosh, in Non-Ferrous Metal Systems. Part 3-LandoltBörnstein-Group IV Physical Chemistry (Springer, Berlin, 2007), pp. 303-337.

23. C. Schmetterer, H. Flandorfer, C. Luef, A. Kodentsov, and H. Ipser, J. Electron. Mater. 38, 10 (2009).

24. O. Carlsson and G. Haegg, Z. Kristallogr. 83, 308 (1932).

25. J. Brandon, W. Pearson, and D. Tozer, Acta Crystallogr. Sect. B Struct. Crystallogr. Cryst. Chem. 31, 774 (1975).

26. J. Lenz and K. Schubert, Chem. Monthly 102, 1689 (1971).

27. W.L. Bragg, Philos. Mag. 28, 355 (1914).

28. H. Knoedler, Metall 20, 823 (1966).

29. H. Knödler, Acta Crystallogr. 10, 86 (1957).

30. Y. Watanabe, Y. Fujinaga, and H. Iwasaki, Acta Crystallogr. 39, 306 (1983).

31. C. Mueller and S. Lidin, Acta Crystallogr. Sect. B: Struct. Sci. Cryst. Eng. Mater. 70, 879 (2014). 
32. A. Westgren and G. Phragmén, J. Inorg. Gen. Chem. 175, 80 (1928).

33. H. Swanson and E. Tatge, Natl. Bur. Stand. 539, 1 (1953).

34. C. Wieser, A. Walnsch, W. Huegel, and A. Leineweber, $J$. Alloys Compd. 794, 491 (2018).

35. Bruker AXS GmbH, TOPAS V. 5.0, Karlsruhe (2004).

36. P. Thompson, D.E. Cox, and J.B. Hastings, J. Appl. Crystallogr. 20, 79 (1987).

37. G.S. Pawley, J. Appl. Crystallogr. 14, 357 (1981).

38. G. Zeng, S.D. McDonald, J.J. Read, Q. Gu, and K. Nogita, Acta Mater. 69, 135 (2014).

39. W. Yang, T. Yamamoto, K. Aso, F. Somidin, K. Nogita, and S. Matsumura, Scr. Mater. 158, 1 (2019).
40. K. Momma and F. Izumi, J. Appl. Crystallogr. 44, 1272 (2011).

41. F.J.J. van Loo, Prog. Solid State Chem. 20, 47 (1990).

42. T. Goedecke, D. Heine, and W. Koester, Int. J. Mater. Res. 63, 802 (1972).

43. S. Sommadossi and A. Fernández Guillermet, Intermetallics 15, 912 (2007).

44. K. Nogita and T. Nishimura, Scripta Mater. 59, 191 (2008).

Publisher's Note Springer Nature remains neutral with regard to jurisdictional claims in published maps and institutional affiliations. 